\title{
Exploration and Practice of College-Enterprise Cooperation in Training Students' Engineering Ability
}

\author{
Qingyue Wei \\ Shanghai University \\ Department of Mechanical Automation Engineering \\ Shanghai, China \\ Weiqy@i.shu.edu.cn \\ Man Meng* \\ Shanghai University \\ Department of Mechanical Automation Engineering \\ Shanghai, China \\ manmanmeng@shu.edu.cn
}

\author{
Ming Li \\ Shanghai University \\ Department of Mechanical Automation Engineering \\ Shanghai, China \\ robotlib@staff.shu.edu.cn \\ Yingzhong Tian \\ Shanghai University \\ Department of Mechanical Automation Engineering \\ Shanghai, China \\ troytian@shu.edu.cn
}

\begin{abstract}
Engineering education is a kind of higher education method that all countries in the world are actively discussing. Cooperation between college and enterprise is an effective way to improve the effectiveness of engineering education. However, in the specific practice process, there are many problems such as training methods and implementation approaches that need to be solved. his article describes Shanghai University, based on CDIO concept, about how to use the 5W2H1E method to analyze the project requirements at the startup phase of college-enterprise cooperation projects and innovatively proposes the fundamental principle of school-enterprise cooperation (REF principle) based on them. Shanghai University and Germany Carle Zeiss have carried out eight years of college-enterprise cooperation and achieved good results.
\end{abstract}

Keywords-Engineering education; CDIO; College-enterprise cooperation; CMM; Talent cultivation mode

\section{INTRODUCTION}

With the development of human society and technology, the demand for high-level engineering talent has become increasingly prominent. Since 2000, many countries in the world have begun to explore the problem on the training of engineering talents in higher education, and gradually formed the concept of CDIO engineering education [1]. In the process of engineering education, the whole research and development process of the product (object) is taken as the carrier, meanwhile, conception, design, realization and operation is controlled [2].

While stimulating students' initiative, the CDIO engineering education concept of combining the systematic curriculum system with engineering practice emphasizes four aspects: engineering basic knowledge, personal ability, interpersonal skills and engineering system ability [3].At present, this concept has been accepted by many colleges and applied in the actual teaching process.
Although in domestic universities everyone has explored the model of cooperation between college and enterprise and has achieved some results, it is quite difficult to really implement engineering education and achieve the desired effect, because the restriction of the school's own engineering teaching resources and the partner company's social responsibility.

This article describes the research and implementation results achieved by Shanghai University after ten years exploration in this area.

II. TECHNICAL ANALYSIS OF ENGINEERING PERSONNEL TRAINING METHODS IN COLLEGE-ENTERPRISE COOPERATION

How should modern university students develop the basic knowledge of engineering, personal ability, interpersonal team ability, and engineering system ability in a short period of four years? There are too many issues to be considered. Therefore, according to the training objectives (requirements), the $5 \mathrm{~W} 2 \mathrm{H} 1 \mathrm{E}$ method is adopted here. A systematic and comprehensive analysis is conducted on the needs of engineering education and the core issues involved.

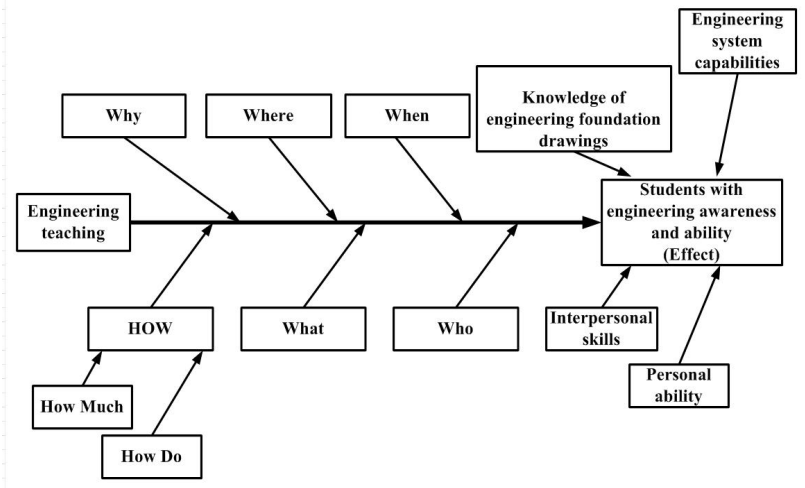

Fig. 1. Analysis and Application of 5W2H1E Method 
The so-called $5 \mathrm{~W} 2 \mathrm{H} 1 \mathrm{E}$ is an innovative technique that asks detailed questions from the perspectives of What, Where, When, Who, Why, How much, How Do, and Effect. Using this method (Fig. 1) allows us to examine response to demand and summary of related problems in a comprehensive manner during cooperation between college and enterprise. Based on this, this paper explores methods that need to be cracked and dealt with in the implementation.

1) It is the core issue of the whole project to choose what kind of enterprises to cooperate with, which will determine the ultimate goal, the result and the height of students' training. Therefore, in the selection of cooperative enterprises, we need to consider the culture of the cooperative enterprise and the benefit of the enterprise in this kind of activities in addition to the professional and technical content of the enterprise and the advanced technology [4];

2) There is a certain difference between the school teaching system and the enterprise management system. In order to achieve a good teaching effect, we must consider such factors as professional technology, teaching link, practice link, enterprise requirement and student management [5];

3) At present, the credit system and the elective system are generally adopted in Colleges and universities. How to embody the characteristics and advantages of the course so as to attract the students to actively participate in this kind of curriculum under the circumstances of the students' independent choice?

4) How to tranin,evaluate and reflect the Students' four levels of competence in the CDIO concept?

5) What kind of process mechanism needs to be constructed in order to make this type of curriculum sustainable and continuously optimize and improve is an important part of this course in the process of college-enterprise cooperation[6]?

6) The school has the support of a large number of scientific research teams. The company has advanced equipment and the latest information on social needs. To build a complete teaching environment and play its greatest role through effective input, Making full use of the respective resources of the school and enterprise is necessary [7].

These problems are the core issues that must be taken seriously and effectively handled in the engineering teaching of school-enterprise cooperation. they are also the focus of this paper.

\section{DISCUSSION ON THE IMPLEMENTATION PATH OF ENGINEERING PERSONNEL TRAINING METHODS IN COLLEGE- ENTERPRISE COOPERATION}

After the application of the 5W2H1E method, we listed all the issues that need to be addressed and solved. However, in the specific solution process, these issues need to be summarized accordingly so that corresponding solutions can be proposed in a targeted manner.

First of all, from a certain perspective, education is a kind of public welfare activity but it is not the main business of a company. Therefore, it is certain that the enterprises which are willing to participate in are socially responsible. What companies can benefit from the activities are the qualified students with engineering awareness and technical skills developed under the engineering education model.

Secondly, which technology is positioned is a common concern of schools, students, and companies. The curriculum needs to not only attract the students but also meet the needs of the society, In particular, the needs of company is an important factor in the success of this type of project, because only in this way can students, schools, and companies participating in the project benefit from it.

Thirdly, what kind of professional and technical skills schools need to have in carrying out such activities? The school's education has its own regularity. At the same time, there should be schools to undertake the smooth convergence between courses. To meet the needs of the society in urgent need of talented people, schools are required to have corresponding professional and technical skills. Therefore, the professional skills and abilities of schools are also the key concerns of enterprises. It is also the basis for cooperation between the school and the enterprise.

From the above analysis, there are several obvious technical characteristics in this type of cooperation:

\section{A. Relatedness}

It should be the addition and expansion of existing courses so that students can learn more advanced technology and engineering knowledge in the premise that students can further grasp the existing knowledge. This is also the purpose of adhering to the school in order to prevent school-industry cooperation for school-enterprise cooperation. Of course it is also a guarantee for the continuous cooperation of such cooperation;

\section{B. Engineering}

Only in this way can schools and enterprises be closely linked to form the whole process engineering teaching from theory to engineering practice.

\section{Frontier}

This will create new knowledge points, link social needs, and make it a point of convergence for concerned parties.

The above points can be attributed to three basic points during college-enterprise cooperation: relatedness, engineering, and frontier namely REF principle. According to the REF principle, the analysis and research from the various dimensions are carried out to determine the final implementation point of our school-enterprise cooperation:

1) According to the research and development of mechanical engineering trends, especially the development and application trend of digital technology, the cooperation direction will be centered on digital technology, which will make the cooperation project advanced and frontier;

2) The school organizers conducted targeted research on the needs of the society and enterprises for professional and technical personnel. Thus, it is clear that the digital technology 
of mechanical product quality is the breakthrough point, that is to say, taking professional and ability teaching of digital detection technology as the grasp of the hand.

3) The school focused on analyzing and investigating the technical advantages and teaching resources in this field. Because the related scientific research team has accumulated experience in digital detection technology. They also has longterm cooperation with almost all the major suppliers in the industry. Therefore, this article confirms the idea of focusing on Geometric digital measurement (Coordinate Measuring Machine) technology, seeking suitable companies and carrying out related school-enterprise cooperation teaching.

Based on the above considerations and taking into account the school's existing teaching and scientific research equipment such as coordinate measuring machines, Shanghai University and the German company Zeiss discussed the possibility of school-industry cooperation in the development of talents for geometric digital measurement.

In fact, world-class companies like Zeiss of Germany have a sense of social responsibility. They hope to contribute to the training of measurement professionals in China. They also hope to provide conditions for the company's own talent selection. But as large companies, they also hope that this is a long-term task. To this end, Zeiss Germany made a serious and comprehensive assessment of the relevant capabilities of Shanghai University. In this assessment process, Shanghai University has played a decisive role in scientific research capabilities and influence in the industry.

\section{EXPERIENCES AND RESULTS OF ENGINEERING PERSONNEL TRAINING METHODS IN COLLEGE-ENTERPRISE COOPERATION}

It is precisely because the school and the company have carried out very serious preliminary thoughts and studies on the project of cooperation in carrying out engineering teaching, which provided the basis for the follow-up of the entire operation. In the course of the development of specific teaching activities, there are quite a few specific issues that need to be resolved effectively. This involves the design and development of specific teaching methods:

1) In order to make the project work properly, both sides first set up a special management team to coordinate the various coordination needs that emerged throughout the teaching process;

2) The two sides jointly have established a teaching group that includes professors, engineers and full-time engineers of the company to ensure the theoretical and practical activities of the curriculum;

3) Shanghai University has set up specialized elective courses, and has formulated a syllabus that integrates with the existing curriculum system and targets the world's most advanced measurement technology and measurement standards;

4) The two parties carefully designe the curriculum practice sessions, which mainly include the theoretical teaching and experimental operation contents of the school and oneweek on-site internship at the German Zeiss Shanghai base.
During the company's one-week on-site internship, the company mobilizes four the latest measuring machine each year and equipes with 2 engineers to participate in teaching training;

5) the two sides have worked out a special academic monograph(Textbook), " Geometrical Digital Measurement Techniques and Applications" which the first teaching material in China that completely introduces digital measurement (three-coordinate measurement);

6) The two sides jointly designed the assessment methods for the courses. The content and methods of assessment in theory and experiments are mainly conducted according to the requirements of the school, while internships in the enterprise are conducted according to the standards of the enterprise. The assessment is conducted in the form of a team. The contents of the assessment involve personal capabilities, team cooperation, and problem-solving abilities so that the assessment of the entire course involves the basic requirements and main contents of engineering education. Students who have passed the assessment will receive the qualification certificate for measuring operation and programming issued by ZEISS. These certificates provide students with a good ability proof of employment.

It is worth mentioning that German Zeiss has also set up special scholarships in schools to reward outstanding students and teachers in engineering teaching. Schools and enterprises have invested a lot of manpower and resources in the project implementation process since 2010 and more than 300 engineering students who master the professional skills of coordinate measurement have been trained. Among them, a considerable number of students participated in the graduation project of the cooperation between Shanghai University and Zeiss. So far, nearly 10 students have joined the Carl Zeiss Company in Germany.

The course of the project has become part of the excellent course in Shanghai. At the same time, the project has been awarded the two prize of Shanghai teaching achievement award. The cooperation teaching material of the two sides have totally issued more than 2 million books. The project's cooperation has received constant attention from the society and the media, including the Shanghai Municipal Government website and the Jiefang Daily, as well as the industry's mainstream technology media.

\section{CONCLUSION}

It may not be difficult to be a school-enterprise cooperation program but it is difficult to continue cooperation for many years and make it really useful. The successful cooperation between Shanghai University and Zeiss of Germany comes from the responsibility of the two parties to the society; from the effective application of the 5W2H1E technique and innovativly proposed REF principles, and it also stems from the dedication of both parties to the implementation of the project. This successful case which has been lasted for 8 years and is still continuing to cooperate, has reference significance for the development of school-enterprise cooperative engineering education activities. 


\section{REFERENCES}

[1] Zhong Shouxian, Zhang Ying, Guo Shaohui, Exploration and practice of the MPC-CDIO Engineering Education Model. Research in Higher Education of Engineering, Vol.2.pp 169-175 .2015. (In Chinese)

[2] Kang Quanli, Ding Feiji, A Retrospect and Reflection on the Research into the CDIO Engineering Education in Chian. Research in Higher Education of Engineering, Vol.4.pp 40-46.2016. (In Chinese)

[3] Qi Xie, Yi Deng. Research of Talent Training Mode for Cooperation Between Colleges and Enterprises in Implementing "Excellent Program". Journal of Hunan Institute of Engineering, Vol. 1, pp. 106 - 108. 2013. (in Chinese)

[4] Wang Zhanao, Qian Chong, Ye Chunshuang. A Probe into the Training Mode of School-Enterprise Symbiotic Cooperation with Innovation and
Entrepreneurship. Education theory and practice. Vol. 38(06)pp1214.2018. (In Chinese)

[5] Hua Xiaoyang, Wang Wenkui, Jiang Shengyong. On the Issues Relating to Cultivating Application-oriented Engineering Talents through University-Enterprise Cooperation. Research in Higher Education of Engineering, Vol.1.pp91-212.2013. (In Chinese)

[6] Z.Y. Li, H. Zhu, Z.J. Liu. Guiding the Reform of Higher Engineering Education with Result-oriented Educational Ideas. Research in Higher Education of Engineering, Vol. 2, pp.29-34, 2014 . (In Chinese)

[7] Liu Xiping, Zhou Zhijun, Study 'of Cooperative Pattern between College and Enterprise for Applied Undergraduate Colleges. Journal of Jixi University, Vol. 12, pp. 16 - 17.2011. (in Chinese) 